\title{
The Mediating Role of Burnout in the Relationship between Communication Skills and Emotional Divorce among Married Employees in Ahvaz Oil Company (2014-2015)
}

\author{
Fariborz Sedighi Arfa-ee \\ Department of Psychology, University of Kashan, Kashan, Iran \\ Email: Fsa@kashanu.ac.ir \\ Mohammad Reza Tamannai Far \\ Department of Psychology, University of Kashan, Kashan, Iran \\ Email: Tamannai@kashanu.ac.ir
}

\author{
Ali Mohammad Fallahi \\ Faculty of Foreign Languages and Literature, University of Kashan, Kashan, Iran \\ Corresponding Author Email: fallahimer@yahoo.com \\ Maryam Biglary \\ Department of Psychology, University of Kashan, Kashan, Iran \\ Email: biglary_maryam@yahoo.com
}

Doi:10.5901/mjss.2015.v6n6s6p367

\section{Abstract}

This paper aimed to study the mediating role of burnout in the relationship between communication skills with emotional divorce among married staff in Ahvaz Oil Company. Participants in this study were 300 (263 males and 37 females) who were selected randomly. These participants filled in Maslash Burnout Inventory, Queendom Communication Inventory, and Emotional Divorce Scale. To test the hypothesis of the study, path analysis was used with AMOS software. Results approved above-average fitting to the model with data and the research hypothesis was conformed. Findings also showed that there was a significant negative relationship between communication skills and emotional divorce, and communication skills and burnout. There was a significant positive relationship between burnout and emotional divorce. It was concluded that burnout could be placed as a mediator variable in the relationship between communication skills and emotional divorce accelerating the process of emotional divorce

Keywords: Emotional divorce, Burnout, Communication skills

\section{Introduction}

Family, as the first socializing institution, plays an important role in society so that social problems are in close contact with the influence of the family. Divorce is one of the social problems which has turned from a private involvement into a public issue (Safa-ee Rad \& Varasteh Far, 2013). Iran is currently experiencing an unexpected increase of divorce (Forootan \& Jadid Milani, 2008, quoted by Shakerian, 2014); in addition to increasing legal divorce in the country, a new phenomenon called emotional divorce has also widely spread (Yavari, 2004, quoting by Doorfard, 2012). According to the official statistics presented, the number of emotional divorces exceeds legal ones and it can be said that emotional divorce is one of the important factors in the failure of the most basic structure of society, i.e. family (Gharacheh, Azadi, \& Afrasiyabi, 2011). Although the couple (in emotional divorce) continue to live together as a social group, they do not feel attracted towards each other anymore, their relationships are broken, or there are no desires and satisfactions between them (Bokhara-ee, 2005, quoted by Zeinali Pour \& Abdi, 2014). This issue represents a problem in the correct relationship between the couple and it can be spread to the family and across the society distorting human relations (Bastani, Golzari, \& Roshani, 2010), whereas to interact and communicate with others is a basic human psychological need (Tagay, Baydan \& Voltan, 2010, quoted by Yildaz \& Duy 2013). This issue is so important that a significant portion 
of job satisfaction and satisfaction with the family life depends on the quality of relationships with others (Fat'hi, 2005, quoted by Azizi, 2011) and complex life problems have doubled the importance of communication (Farber, 2000, quoted by Ahmadi, 2013). Effective interpersonal communication requires interpersonal communication skills (Gardner, 1983, quoted by Suhaimi, Marzugki \& Mustaffa, 2014) which, as the basis of other skills (Korkut, 2004, quoted by Ozkan et al., 2014), are referred to behaviors that help individuals properly express their emotions and needs and achieve personal goals.

These skills are so importance that lacking them can lead to loneliness, anxiety, depression, low self-esteem, and a failure in career success (Farber, 2000, quoted by Ahmadi, 2013).

In this respect (the relationship between communication skills with emotional divorce) some basic and review research has been conducted. For example, the study carried out by Bastani, Golzari, and Roshani (2010) showed that emotional divorce is not a single-factor phenomenon and different factors affect it; one of these factors is deficiency in communication skills. Imani (2012) also studied the most common causes of emotional divorce and noted that failure in life skills and deficiencies in communication skills are among reasons which led to emotional divorce. There are, of course, studies which suggest that there is a relationship between communication skills and concepts such as conjugal satisfaction and marital happiness and concord which overlap with the concept of emotional divorce, or at least are among the most important factors affecting it (Ala-ee, Ahmadigatab, \& Baba-ee, 2011; Nasseri \& Baba-ee, 2014; Kazemi \& Nik Manesh, 2011; Askari, 2012). On the other hand, the stressful world today has tied life's work and family together. Kinnunen (1996) believes that the quality of family life can be transferred to other areas of life such as occupation and can positively or negatively influence it or be influenced by it (Rahpeima, Kazemi, \& Sohrabi, 2012). One of the factors that affect the functions of the family and can reduce couple's quality of life is burnout (Maghsoodi \& Mohammadi, 2010). In this regard, Yizhong and Chuikai (2007) in their research on the impacts of work and family conflicts concluded that conflict occurs in both structures and the impact is bilateral. Moreover, Agnostopoulos and Niakas (2010) in their study on the relationship between burnout and quality of life and sickness absence among nurses concluded that burnout has a negative impact on family life. Generally, burnout dramatically affects the personal and organizational life (Khaza-ee, 2004, quoted by Zeinali Pour \& Abdi, 2014), and according to research carried out in this area it can affect marital or familial relationships (Rahpeima, Kazemi, \& Sohrab, 2012). IResearch has shown that burnout is not related to a specific profession and all employees are at risk (Schoufeli, 2008, quoted by Reis, Xanthaopoulou, \& Tsaousis, 2015). This syndrome can remain stable in a period of five, ten, or even fifteen years (Hakanen, Bakker \& Jokisaari, 2011). It is contagious and is defined as long-term continuous stress that people experience in their professional and social lives (Gold \& Bachlon, 2001; quoted by Koruklu et al., 2012). Burnout (as a syndrome) includes three dimensions of emotional exhaustion, depersonalization, and reduced personal accomplishment (Magalhaes et al., 2014). The key symptom of this syndrome is emotional exhaustion which is a common reaction to stress (Sonnentage, 2010; Kiekkas, 2010, quoted by Zeinali Pour, 2014; Adriaenssens, Degucht, \& Meas, 2015). People who suffer from this syndrome cannot function properly in their work environment, and their physical health and mental performance are ruined (Bakker, Demerouti, \& Sanzvergel, 2014). Many factors can cause burnout including 'ineffective communication skills' (Bragard et al., 2006). Many researchers have regarded communication skills as a comparative factor which can moderate job stress (Ahmadi et al., 2013). Results of many studies (Akif Afyon \& Isikdemir, 2013; Ahmadi et al., 2013; Emlod et al., 2011; Reza-ee, Hosseini, \& Khoshknab, 2006), on the relationship between job stress, burnout, and communication skills all corroborated this idea. Therefore, considering the importance of the above (communication skills, emotional divorce, and burnout) visà-vis individual and social health and wellbeing, and accepting the fact that emotional divorce fills the home environment with stress (Akbari et al., 2012), this paper sought to study the mediating effect of job burnout in the relationship between communication skills and emotional divorce.

\section{Method}

This study is a correlation research which aims to determine the mediating role of burnout in the relationship between communication skills and emotional divorce among married employees of Ahvaz Oil Company.

\subsection{Participants}

Based on Morgan table, 300 participants (263 males and 37 females) were selected through systematic random sampling from among the study population (2500 married employees in Ahvaz Oil Company). Questionnaires were distributed among participants and were collected after completion. 


\subsection{Instruments}

\subsubsection{Queendom Communication Inventory:}

This questionnaire was developed by Queendom (2004) to assess communication skills in adults. It has 34 items and measures five secondary skills including listening skills, understanding verbal and nonverbal message, insight to communication, assertiveness, and emotional regulation. Participants responded to each item based on a five-point Likert scale from 1 (Never) to 5 (Forever). Therefore, the possible score for each participant ranged between 34 to 170. Items 2 , 4 , and 6 were scored in reverse. Hosseinchari and Fadakar (2005) reported the reliability and validity of this questionnaire 0.69 and 0.71 respectively using Cronbach's alpha.

\subsubsection{Maslach Burnout Inventory:}

This questionnaire has been made by Maslach (1981). The questionnaire includes 22 items and measures three dimensions of emotional exhaustion, depersonalization, and personal accomplishment. Respondents answered each item based on a seven-point Likert scale from 0 (Never) to 7 (Very much). Abedi (2004) reported a reliability of 0.80 for emotional exhaustion, 0.69 for depersonalization, and 0.79 for personal performance (Abedi, 2004, quoted by, Hoshyar, Bardideh, \& Mir Jafari, 2013).

\subsubsection{Emotional Divorce Scale (EDS):}

This questionnaire was designed by Gottman (1995) and has 24 items. Respondents choose between 'Yes' and 'No' (which are scored 1 and 0 respectively) to specify their answers on emotional divorce. Using Cronbach's alpha, Bayat Mokhtari (2013) reported a reliability of 0.91 for this questionnaire.

\section{Findings}

Table 1 below represents the mean and standard deviation values of communication skills, burnout, and emotional divorce according to participants' gender.

Table 1. Mean and Standard Deviation Values of Communication Skills, Burnout, and Emotional Divorce According to Participants' Gender

\begin{tabular}{|llccc|}
\hline Variable & Gender & No. & Mean & SD \\
\hline \multirow{3}{*}{ Communication Skills } & Female & 37 & 101.67 & 7.67 \\
& Male & 263 & 99.11 & 10.37 \\
& Total & 300 & 99.40 & 10.10 \\
Burnout & Female & 37 & 98.40 & 16.70 \\
& Male & 263 & 99.22 & 17.81 \\
& Total & 300 & 92.12 & 17.66 \\
Emotional divorce & Female & 37 & 3.67 & 3.67 \\
& Male & 263 & 4.60 & 4.60 \\
& Total & 300 & 4.49 & 5.16 \\
\hline
\end{tabular}

Results showed that women had a higher mean in communication skills and a lower one in burnout and emotional divorce in comparison with men.

Table 2. Correlation Coefficient Matrix between the Variables (Communication Skills, Burnout, Emotional Divorce)

\begin{tabular}{|l|}
\hline Variables 1223 \\
\hline 1. Communication Skills 1 \\
2. Bumout $-0.14 * 1$ \\
3. Emotional Divorce \\
*P $\leq 0 / 05 * \mathrm{P} \leq 0 / 01$
\end{tabular}


As Table 2 shows, there is a significant negative correlation between communication skills and emotional divorce ( $P$ $<0.05, r=-0.12)$, there is a significant positive correlation between burnout and emotional divorce $(P<0.01, r=0.14)$, and there is a significant negative correlation between communication skills and burnout $(P<0.05, r=-0.14)$. In other words, by increasing the communication skills, burnout and emotional divorce decrease and with an increase in burnout, emotional divorce increases too. To test the research hypothesis about the mediating role of burnout in the relationship between communication skills with emotional divorce, path analysis using AMOS software was used.

The direct impact of communication skills on emotional divorce was significant $(\beta=-0.127, P=0.025)$. But the question was if the indirect effect was significant too? To answer this question, the conceptual model of the research was developed which is presented in Figure 1.

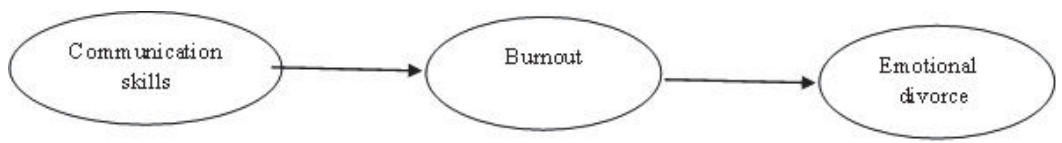

Figure 1. The conceptual model of the mediating role of burnout in the relationship between communication skills with emotional divorce.

Table 3. Direct and Indirect Impacts of Variables on the Criterion Variable

\begin{tabular}{|lccc|}
\hline Impact & $\begin{array}{c}\text { Non-standardized } \\
\text { coefficient (B) }\end{array}$ & $\begin{array}{c}\text { Standardized } \\
\text { coefficient ( } \boldsymbol{\beta})\end{array}$ & $\begin{array}{c}\text { Sig. } \\
\text { level }\end{array}$ \\
\hline Direct impact of communication skills on burnout & 0.0254 & -0.145 & 0.037 \\
Direct impact of burnout on emotional divorce & 0.044 & 0.149 & 0.002 \\
Indirect impact of communication skills on emotional & -0.011 & -0.022 & 0.016 \\
divorce through burnout & & & \\
\hline
\end{tabular}

As it can be seen in Table 3, the indirect impact of communication skills on emotional divorce through burnout is significant and inverse $(\beta=-0.022, P=0.016)$. Model direct coefficients are also significant.

Generally, the coefficients for each of the two endogenous (criterion) variables (burnout, emotional divorce) for the research model totaled 2 percent $\left(R^{2}=0.02\right)$. It should be noted that in the presence of burnout variable in the model, if the direct path was outlined for communication skills towards emotional divorce, the direct impact of burnout on emotional divorce would be insignificant $(\beta=-0.108, P=0.098)$.

Table 4. Path Model Fitting Indices

\begin{tabular}{|cccccccc|}
\hline RMSEA & AGFI & GFI & CFI & X2/df & df & P-value & $X^{2}$ \\
\hline 0.091 & 0.954 & 0.992 & 0.817 & 1.49 & 1 & 0.062 & 3.49 \\
\hline
\end{tabular}

There is no common consensus among experts on fitting indices (Weston \& Gore, 2006). But, generally, CFI, GFI, and AGFI indices and those more than 0.90 represent perfect fitting of the model and those above 0.80 represent a relatively good or an average fitting of the model (Kline, 2005). Similarly, if $X^{2} /$ df is less than 3 (Weston \& Gore, 2006), and RMSEA is less than 0.10 (Brown \& Cudeck, 1992, quoted by Gera-ee, Piroozmand, \& Siyamaki, 2014), or less than 0.06 (Hu \& Bentler, 1999), the model has a good fitting.

Based on Table 4 and according to the above discussion, the path model fitting indices confirm an above-average fitting of the model to the data. Based on these findings, the research hypothesis (proposing the mediating role of burnout in the relationship between communication skills and emotional divorce) is confirmed.

\section{Discussion and Conclusion}

This paper aimed to study the mediating role of burnout in the relationship between communication skills and emotional divorce among married employees in Ahvaz Oil Company. The findings of the study confirmed the mediating role of burnout in the relationship between communication skills and emotional divorce. The results showed that there was a significant negative relationship between communication skills and emotional divorce. This is consistent with research 
conducted by Bastani, Golzari, and Roshan (2010), Imani (2012), Ala-ee et al. (2011), Naseri and Baba-ee (2014), Kazemi and Nick Manesh (2011), Askari (2012). To explain this finding regarding research conducted in this area, it can be said that 'communication' is the cornerstone of a healthy and successful family. Personality, learning, confidence, and rational decision making are all affected by communication patterns and can also be one of the main roots of family problems (Olliver and Miller, 1994, quoted by Gholamzadeh, Attari, \& Shafiabadi, 2009). Research showed that communication skills could reduce marital discord and conflicts whereas the growth of such conflicts would end in disinterest and disrespect towards a spouse (Tavakkolzadeh, Negatian \& Soori 2015; Stanley, 2003; Gottman, 2004; Cohen, 2005; quoted by Hossein Khan Zadeh \& Yeganeh, 2013). Reducing such conflicts, on the other hand, would decrease mental health problems (Galinsky \& Waite, 2014), depression (Wang, Wang, \& Miller, 2014), and impaired sexual function (Metz \& Epstein, 2002).

It can increase marital satisfaction and marital adjustment through provoking cognitive responses and impact on behavior (Oprisan \& Cristae 2012; Pourheydari et al., 2013; Ala-ee, Ahmadigatab, \& Babaee, 2011, Naseri \& Baba-ee, 2014; Kazemi \& Nick Manesh, 2011; Askari, 2012). It can also create intimacy in couples and increase emotional and affective involvement (Gholamzadeh, Attari, \& Shafiabadi, 2009).

Research also suggests issues as the causes of emotional divorce including: lack of attention to the emotional needs of the spouse, disregard and disrespect towards the spouse, marital conflicts, violent behavior, sexual dissatisfaction, lack of mental balance and having mental health problems, and deficiencies in communication skills (Bastani, Golzar, \& Roshan, 2010). Moreover, criteria for emotional divorce included intimacy, sexual satisfaction, couples' positive and negative emotions, marriage stability, clinical symptoms such as anxiety and depression (Akbari et al., 2012). Regarding the above-mentioned impacts of communication skills, it can be concluded that training/teaching communication skills (and influencing these factors) can affect emotional divorce.

The results of this research showed that there is a significant negative relationship between communication skills and burnout. This finding is in line with studies conducted by Akifafyon and Isikdemir (2013), Emlod et al. (2011), Ahmadi et al. (2013), and Reza-ee, Hosseini, and Khoshknab (2006) who all concluded in their studies that communication skills could alleviate job stress and reduce burnout. Communication between colleagues is a source of emotional support and of great importance. The more established the relationship is, the fewer employees are likely to undergo stress. In fact, adequate social support protects the individual like a shield from the negative effects of stress. When the relationship between colleagues is weak, the staff feel agitated and unsupported leading to experiencing job stress (Ras, quoted by Ahmadi et al., 2013). While teaching communication skills to individuals helps them define and clear their expectations of others and adapt their expectations to new situations. An effective and efficient relationship in the workplace and a positive perception of the work environment both hinder emotional exhaustion, increase self-actualization, and reduce burnout (Emlod, 2011) while ineffective interpersonal communication creates stress, and stress ensues consequences such as physical ailments, mental disorders, and exhaustion (King, quoted by Ahmadi, 2013). The results of the current study also showed that there was a significant positive relationship between burnout and emotional divorce. This result is consistent with the research carried out by Zeinalipour and Abdi (2014), Yizhong and Chuikai (2007), and Rahpeima, Kazemi, and Sohrab (2012).

Job stress which is the main factor of burnout (Khalefi, Tangestani, \& Osanloo, 2014; Tuna \& Baykal, 2014) creates job dissatisfaction (Lin et al., 2009; Ahmadi, Iranian, \& Parsanezhad, 2011) and also affects marital satisfaction (Mansouri, Mehrabi Zadeh, \& Honarmand, 2009, quoted by Rahpeima, Kazemi, \& Sohrabi, 2012; Robert \& Levenson, 2001; Maghsoodi \& Mohammadi, 2010; Ebrahimi, Nafar, \& Keramati, 2013; Osharoff, 2011). Job satisfaction has a significant influence in family life satisfaction so that people having job dissatisfaction suffer from much stress in their marital life. Continuous exposure to job stress makes job a priority to conjugal relationship. Couples will unconsciously expect their spouses to understand their job stress and the repetition of this issue over time will cause loss of love and commitment between the couples (Paniz, 1996, quoted by Maghsoodi \& Mohammadi, 2010). Job stress of each of the couples will also create emotional and physiological atmosphere in which both wife and husband exhibit many symptoms associated with distress in marital life and a likely separation in the future. In other words, job stress can affect other areas in life including the quality of relationships and marital satisfaction (Robert \& Levenson, 2001). In the same vein, an individual who experiences depression as a result of burnout will also show no interest in allocating time for the family (Raheb et al., 2007).

The research results, on the other hand, showed that there was a negative relationship between job stress, burnout, and mental health (Wang, Kong, \& Chaire, 2011; Peiman Pak et al., 2012; Moghimi, Chamanzamin, \& Maghsoodi, 2013; Einal, 2014). Mental health increases life satisfaction, hence marital satisfaction. Therefore, enhancing mental health will increase marital satisfaction; this relationship is bilateral (Peiman Pak et al., 2012). The research results also revealed that burnout created marital dissatisfaction (Maghsoodi \& Mohammadi, 2010) leading to cold family 
relationships and reducing partner's sexual satisfaction (Pines \& Nures 2003). Burnout negatively correlated with family functions and reduced emotional interaction and emotional response (Raheb et al., 2007; Mohsenzadeh, Kiamanesh, \& Goudarzi, 2008).

Therefore, it can be mentioned that burnout affects the process of initiating and experiencing emotional divorce. In general, according to the findings of this study and based on research which was presented, it can be concluded that burnout can be placed as a mediator variable in the relationship between communication skills and emotional divorce accelerating the process of emotional divorce.

This study had some limitations. The results of this study are not particularly applicable to all organizations with different characteristics so it is necessary to replicate such research in other organizations and different working situations to make sure whether such relationships exist in similar contexts.

\section{References}

Adriaenssens, J., Degucht, V., \& Meas, S. (2015). Determinant \& prevalence of burnout in emergency nurse: A Systematic Review of 25 Years of Research. International Journal of Nursing Studies. 52. 661-669.

Agnostopoulos, F., \& Niakas, D. (2010). Job burn health- related Quality of life \& sickness absence in Greek health professionals. Journal Article. 940-943.

Ahmadi, A., Iranian, S. J., \& Parsanejad, M. (2011). The relationship between organizational creativity and job satisfaction with job stress among the staff in Agriculture Organization in Fars Province. Journal of Modern Industrial/Organizational Psychology. 2(8). 7184.

Ahmadi,O., Ahmadi, M., Elyasi, F., Ahmadi, A., \& Ahmadi, N. (2013). The relationship between burnout and nurses' communication skills. Journal of Mazandaran University of Medical Sciences. 23(106). 130-139.

Akbari, E., Poor Sharifi, H., Azimi, Z., Fahimi, S., \& Amiri Bichakolahi, A. (2012). The effectiveness of group therapy, transactional analysis on satisfaction, adoptability, positive emotions, and intimacy among couples with emotional divorce. Journal of family counseling and psychotherapy. 4. 445-484.

Akifafyon, Y., \& Isikdemir, E. (2013). Examination of relationship between communication skills, burnout levels \& satisfaction levels of football coaches. International Journal of Human Sciences. 10. 1706-1716.

Alayi, Z., Ahmadigatab, T., \& Babaee, A. (2011). Relationship between communication skills \& marital adaptability among university students. Procedia- Social \& Behavioral Sciences. 30. 1959-1963.

Askari, M. (2012). Comparing the effects of communication \& conflict resolution skills training on marital satisfaction. International journal of Psychological Studies. 4.182-195.

Azizi, S. (2011). The relationship between monthly salary and marital satisfaction regarding burnout in junior high school teachers of Dehgolan in 2010-2011. Master's thesis . Career counseling group. Allameh University.

Babaee, H., \& Nasri, L. (2014). Role of social skills in improving the women marital adjustment in the city of sanandaj. International letters of social \& humanistic sciences.19.60-68.

Bakker, A. B., Demerouti, E., \& Sanz Vergel, A. I. (2014). Burnout \& work engagement: The JD-R Approach. Annual Review of Organizational Psychology \& Organizational Behavior. 1. 389- 411.

Bastani, S., Golzari, M., \& Roshani, Sh. (2010). Emotional divorce: the mediating causes and conditions. Iranian Journal of Social Problems. 1(3). 1-20.

Bayat Mokhtari, S. (2013). The effect of group reality therapy in reducing emotional divorce and its psychological effects. Master's Thesis Mashhad Ferdowsi University.

Bragard, I., Razavi, D., Marchal, S., Merckaert, I., Delvavx, N. Libert, Y. (2006). Teaching communication \& stress management skills to junior physicians dealing with cancer patients a Belgian interuniversity curriculum. Support Care Cancer. 14. 454- 461.

Doroodfar, M. S. (2012). The relationship between emotional divorce and legal action get a divorce among couples attending the Family Court. Master's Thesis. Department of Sociology. Islamic Azad University of Tehran.

Ebrahimi, F., Nafar, N., \& Keramati, R. (2013). The relationship between marital satisfaction \& job satisfaction among employees of social welfare organization at Tehran branches. Life Science Journal. 65. 804-812.

Einal, B. (2014). The relationship between work- stress, psychological stress \& staff health \& work outcomes in office workers. Psychology. 5.1301-1311.

Emlod, C., Schneider, N., Meller, I., \& Yagil, Y. (2011). Communication skills, working Environment \& burnout among oncology nurse. European Journal of Oncology Nursing. 15. 358-363.

Galinsky, A. G., \& Waite, L. J. (2014). Sexual activity \& psychological health as mediators of the relationship between physical health \& marital quality. J Gerontol B Psychol SCI SOC SCI GBT, 165, First Published Online January 27.

Gera-ee, E., Piroozmand, M., \& Siyamaki, S. (2014). Analysis of customers' satisfaction in academic (university) libraries with Magal model: A case study of Shahid Chamran University Central Library in Ahvaz. Journal of Librarianship. 3(7). 287-302.

Gharache, M., Azadi, Sh., afrasiyabi, A. (2011). Spouse ill-treatment and the quality of marital life. Journal of Thought and Behavior. 5(19). 55-64.

Gholamzadeh, M., Ali Attari, Y., \& Shafi Abadi, A. (2009). The effectiveness of teaching communication skills on family effectiveness among couples attending Ahvaz Welfare Center. Journal of Knowledge and Research in Applied Psychology. 41. 87-110. 
Hakanen, J., Bakker, A. B., \& Jokisari, M. (2011). A 35 years follow-up study on burnout among Finish employees. Journal of Occupational Health Psychology. 16. 345-360.

Hoshyar, M. R., Bardideh, M.R., \& Mir Jafari, A. (2013). The relationship between resilience, emotional intelligence, and burnout among employees in Shiraz Welfare Organization. Journal of Industrial and Organizational Psychology. 15(4). 49-63.

Hossein Chari, M., \& Fadakar, M. M. (2005). Comparison-based Relationship among pupils and university students. Danesh Raftar Journal of Shahed University. 21(15). 12-32.

Hossein khanzadeh, A. A., \& Yeganeh, T. (2013). The effects of life skills training on marital satisfaction. Procedia: Social \& Behavioral Sciences. 84. 769-772.

Hu, L., \& Bentler, P. M. (1999). Cut-off criteria for fit indexes in covariance structure analysis conventional criteria versus new alternatives. Structural Equation Modelling. 6. 1-55.

Imani, M. (2012). Causes of emotional divorce, its consequences, and ways of dealing with it. Peyvand Journal. 393-395.

Kazemi, Y., \& Nikmanesh, Z. (2011). Predictors of marital adjustment: The Communication Skills \& Sexual Satisfaction. Journal of Indian Academy of Applied Psychology. 37. 162-168.

Khalefi, A., Tangestani, Y. \& Osanloo, SH. (2014). Relationship between job stress \& social support \& burnout in nurse. Journal of Novel Applied Sciences. 3. 48-52.

Khodadadi, E., Ebrahimi, H., Moghadasian, S., \& Babapour, J. (2013). The effect of care self- efficacy, job satisfaction, communication skills rate of nurse in hospitals of Tabriz, Iran. Journal of Caring Sciences. 2. 27-37.

Kline, P. (2005). Principles and practice of modelling (2nd ed.). New York: Guil Ford Press.

Koruklu, N., Feyzioglu, B., Ozenoglu, H., \& Aladga, E. (2012). Teachers burnout levels in terms of some variables. Journal of Educational Sciences: Theory and practice. 12. 1823- 1830.

Lin, Y. H., \& Chen, C. Y. (2009). Physical discomfort \& psychosocial job stress among female operators at telecommunication call centres in Taiwan. Journal of applied erg on. 561.

Magalhaes, E., Olivera, A., Goveia, C., Ladeira, L., Queiroz, D., \& Vieira, C. (2014). Prevalence of burnout syndrome among anaesthesiologists in The Federal District. Jornal of Revista Brasileira De Anestesiologia. 248, 2-7.

Mansoori, Z., \& Mehrabi Zadeh Honarmand, M. (2009). The relationship between mental health problems, job satisfaction, and marital satisfaction among working women. Women and Culture. 1(3). 91-102.

Maqsoodi, M., \& Mohammadi, Sh. (2010). Burnout and marriage boredom (A Case Study: Gynecological female surgeons working in hospitals in Tehran). Women Research Journal. 8(3). 57-71.

Metz, M.A., \& Epstein, N. (2002). Assessing the role of conflict in sexual dysfunction. Journal of Sex \& marital therapy. 28, $139-164$.

Moghimi, F., Chamanzamin, R., \& Maghsoodi, A. (2013). Relationship between job satisfaction \& employees mental health. Procedia \& Behavioral Science. 48. 293-297.

Mohsenzadeh, F., Kiamanesh, A., \& Goodarzi, M. (2008). The relationship between family effectiveness and burnout among primary school teachers in 19 educational zones in Tehran. Quarterly Journal of Career and Organizational Counseling. 2(2). $127-143$.

Oprisan, E., \& Cristae, D. (2012). A few variable of influence in the concept of marital satisfaction. Journal of Social \& Behavioral Sciences.3. 468-472.

Osharoff, A. (2011). Emotional exhaustion, work-family conflict \& marital satisfaction among professional psychology. Masters Theses. Paper 494. http:// Ecommons. Luc.Cdu./ Luc- Theses/ 494

Ozkan, H., Dalli, M., Bingol, E., Metin, S. C., \& Yarali, D. (2014). Examining the relationship between the communication skills \& selfefficacy levels of physical education teacher candidates. Social \& Behavioral Science. 152. 440-445.

Peyman Pak, F., Mansoor, L., Sadeqi, M. S.,\& Taqi Poor, E. (2012). The relationship between job stress, marital satisfaction, and mental health among nurses in hospitals in Tehran. Quarterly Journal of Career and Organizational Counseling. 54. 13-27.

Pines, A., \& Nures, R. (2003). The relationship between career and couple burnout implication for career and couple counseling. Journal of Employment Counseling.7. 50-64.

Pourheydari, S., Bagherian, F., Doustkam, M., \& Bahadorkhan, J. (2013). The effects of life skills training on marital \& sexual satisfaction of young couples. Journal of Knowledge \& Research In Applied Psychology.51. 14-22.

Raheb, Gh., Ra'fati, A., Pasandideh, M., \& Shariati, M. (2007). The relationship between policewoman burnout with their family functions. Journal of Policewoman. 4(1). 38-54.

Rahpeima, N., Kazemi, S. A., \& Sohrabi, N. (2012). The relationship between public health and marital satisfaction with burnout among women working in subordinate governors in Fars province. Journal of Women Sociology (Women and Society). 3(2). 137-162.

Reis, D., Xanthopoulou, D., \& Tsaousis, I. (2015). Measuring job \& academic burnout with the Oldenburg Burnout Inventory (OIBI): Factorial Invariance a Cross Samples \& Countries. Journal of Burnout Research. 16. 11.

Reza-ee, Sh., Hosseini, M. A., Fallahi Khoshknab, M. (2006). The effect of communication skills on nurses job stress among nurses working in rehabilitation centers in Ray, Tehran, and Shemiranat. Tehran University Medical Journal. 64(1). 21-26.

Robert, N. A., \& Levenson, K.W. (2001). The remain of working impact of job stress \& exhaustion on marital interaction in police couples. Journal of Marriage \& Family. 63. 1052- 1067.

Safa-ee Rad, S., \& Varastefar, A. (2013). The relationship between marital conflict and emotional divorce among women attending courts in Eatern Tehran in 2011. Journal of Social Research. 20(5). 85-106.

Shakerian, A., Nazari, A. M., Masoomi, M., Ebrahimi, P., \& Danai, S. (2014). Inspecting the relationship between sexual satisfaction \& marital problems of divorce-asking women in Sanandaj City Family Courts. Procedia Social \& Behavioral Sciences. 114. 327333. 
Suhaimi, A. W., Marzugki, N. A., \& Mustaffa, C. (2014). The relationship between emotional intelligence \& interpersonal communication skills in disaster management context: a Proposed Framework. Procedia Social \& Behavioral. 155. 110- 114.

Tavakolizadeh, T., Nejatian, M., \& Soori, A. (2015). The effectiveness of communication skills training on marital conflicts \& its different aspects in women. Procedia Social \& Behavioral Sciences. 171. 214-221.

Tuna, R., \& Baykal, U. (2014). The relationship between job stress \& burnout level of oncology nurses. Asia - Pacific Journal of Oncology Nursing. 1. 33-39.

Wang, Q., Wang, D., \& Miller, R. B. (2014). Marital satisfaction \& depressive symptoms among Chinese older couples. Aging \& Mental Health. 18. 33-39.

Wang, W., Kong, A., \& Chaire, S. Y. (2011). Relationship between job stress level \& coping strategies used by Hong Kong nurses working an Actute Surgical Unit. Applied Nursing Research. 24. 238-243.

Weston, R., \& Gore, P. A. (2006). A brief guide to structural equation modelling. The Counselling Psychologist. 34. 719-751.

Yildaz, M. A., \& Duy, B. (2013). Improving empathy \& communication skills of visually impaired early adolescents through a psychoeducation. Educational Sciences: Theory \& Practice. 13. 1470- 1476.

Yizhong, Z., \& Chuikai, Sh. (2007). The effects of work family conflict on telecom employees job burnout \& general health. Journal Article. 940- 943.

Zanialipour, H., Zarei, E., \& Abdi, K.(2014). An examination of relationship between job burnout and emotional divorce among managers of industry mines and trade organization of Hormozgan Province. Journal of Applied Environment and Biological Sciences. 4. 111-114. 